\title{
BMJ Open An interview study to determine the experiences of cellulitis diagnosis amongst health care professionals in the UK
}

\author{
Mitesh Patel (D) , ${ }^{1,2}$ Siang Ing Lee, ${ }^{1}$ Nick J Levell, ${ }^{3}$ Peter Smart, ${ }^{2}$ Joe Kai, ${ }^{1}$ \\ Kim S Thomas, ${ }^{2}$ Paul Leighton ${ }^{2}$
}

To cite: Patel M, Lee SI, Levell NJ, et al. An interview study to determine the experiences of cellulitis diagnosis amongst health care professionals in the UK. BMJ Open 2020;10:e034692. doi:10.1136/ bmjopen-2019-034692

- Prepublication history for this paper is available online. To view these files, please visit the journal online (http://dx.doi. org/10.1136/bmjopen-2019034692).

Received 02 0ctober 2019 Revised 30 July 2020 Accepted 07 September 2020

D) Check for updates

(C) Author(s) (or their employer(s)) 2020. Re-use permitted under CC BY-NC. No commercial re-use. See rights and permissions. Published by BMJ.

${ }^{1}$ Division of Primary Care \& National Institute for Health Research, School of Medicine, University of Nottingham, Nottingham, UK

${ }^{2}$ Centre of Evidence Based Dermatology, University of Nottingham, Nottingham, UK

${ }^{3}$ Dermatology, Norfolk and

Norwich University Hospital NHS

Foundation Trust, Norwich, UK

Correspondence to

Dr Mitesh Patel;

mpatel59@doctors.org.uk

\section{ABSTRACT}

Objectives To explore healthcare professionals (HCPs) experiences and challenges in diagnosing suspected lower limb cellulitis.

Setting UK nationwide.

Participants 20 qualified HCPs, who had a minimum of 2 years clinical experience as an HCP in the national health service and had managed a clinical case of suspected cellulitis of the lower limb in the UK. HCPs were recruited from departments of dermatology (including a specialist cellulitis clinic), general practice, tissue viability, lymphoedema services, general surgery, emergency care and acute medicine. Purposive sampling was employed to ensure that participants included consultant doctors, trainee doctors and nurses across the specialties listed above. Participants were recruited through national networks, HCPs who contributed to the cellulitis priority setting partnership, UK Dermatology Clinical Trials Network, snowball sampling where participants helped recruit other participants and personal networks of the authors.

Primary and secondary outcomes Primary outcome was to describe the key clinical features which inform the diagnosis of lower limb cellulitis. Secondary outcome was to explore the difficulties in making a diagnosis of lower limb cellulitis.

Results The presentation of lower limb cellulitis changes as the episode runs its course. Therefore, different specialties see clinical features at varying stages of cellulitis. Clinical experience is essential to being confident in making a diagnosis, but even among experienced HCPs, there were differences in the clinical rationale of diagnosis. A group of core clinical features were suggested, many of which overlapped with alternative diagnoses. This emphasises how the diagnosis is challenging, with objective aids and a greater understanding of the mimics of cellulitis required.

Conclusion Cellulitis is a complex diagnosis and has a variable clinical presentation at different stages. Although cellulitis is a common diagnosis to make, HCPs need to be mindful of alternative diagnoses.

\section{INTRODUCTION}

Cellulitis is a frequent presentation in both the community and secondary care, with $60 \%$
Strengths and limitations of this study

- The research question was developed from research priorities in the cellulitis priority setting partnership, involving patients.

- Participants were included nationally around the UK.

- Participants from various specialties that commonly diagnose cellulitis were recruited.

- Our recruitment strategy is most likely to have targeted healthcare professionals with an interest in dermatology.

- The size and scope of the sample population is a limitation.

of presentations affecting the lower limbs. ${ }^{1}$ However, the diagnosis of cellulitis can be challenging, with up to a third of suspected lower limb cellulitis cases being later diagnosed as other diagnoses. ${ }^{2}$ This results in avoidable hospital admissions and unnecessary antibiotic prescribing ${ }^{3}$ and is further compounded by the lack of validated diagnostic criteria or tools for cellulitis. ${ }^{4}$

A UK cellulitis research priority setting partnership (PSP) determined that improving healthcare professionals' (HCPs) diagnostic accuracy is a key priority for future cellulitis research. ${ }^{5}$ An interview study of people with recurrent cellulitis and lymphoedema suggested that patients often experience difficulties in obtaining a speedy and accurate diagnosis. ${ }^{6}$

The aims of this interview study were to explore the HCP experiences and challenges faced in diagnosing suspected lower limb cellulitis.

\section{METHODS}

Protocol registration and ethics

The final protocol was registered on the Centre of Evidence Based Dermatology 
(CEBD) website (9 May 2019). Ethical approval was granted by the Health Research Authority and Health and Care Research Wales (19/HRA/0485, 30 November 2018). Verbal and written consent was obtained from each participant.

\section{Patient and public involvement}

The research question was developed from research priorities in the cellulitis PSP, involving patients. A patient representative helped design this study and is a coauthor. On publication, participants will be sent the final manuscript.

\section{Eligibility criteria}

\section{Selection of participants}

Participants were qualified HCPs, who had a minimum of 2 years clinical experience as an HCP in the national health service and had managed a clinical case of suspected cellulitis of the lower limb in the UK. Two years' experience was the minimum requirement as then HCPs will have gained adequate exposure to cellulitis cases. HCPs were recruited from departments of dermatology (including a specialist cellulitis clinic), general practice, tissue viability, lymphoedema services, general surgery, emergency care and acute medicine.

Purposive sampling was employed to ensure that participants included consultant doctors, trainee doctors and nurses across the specialties listed above. Participants were recruited through:

1. National networks.

2. HCPs who contributed to the cellulitis PSP.

3. UK Dermatology Clinical Trials Network.

4. Snowball sampling where participants helped recruit other participants.

5. Personal networks of the authors.

Potential participants were approached and recruited by email. Data collection and analysis were undertaken concurrently and sampling ceased when thematic saturation had been achieved (ie, new interviews generated no new insights). ${ }^{7}$

\section{Researcher characteristics}

Interviews were conducted by MP (male), and coded and analysed by MP and SIL (female, both general practitioner (GP) trainees who had managed clinical cases of cellulitis previously). Both MP and SIL attended qualitative methodology training courses. The broader research group included experienced clinical academics (JK (academic GP) and NL (clinical professor of dermatology), a patient representative (PS) and senior qualitative experts (JK and PL)). Three participants had clinical interactions with the interviewer in the past, but not regarding cellulitis.

\section{Interview setting}

Each participant took part in a single, semistructured, qualitative interview. Two interviews were face to face, with the remaining via telephone. Written consent was gained from participants, with additional verbal consent gained before the interview. All participants received a
$£ 20$ reimbursement voucher or donated this fee to the British Skin Foundation charity.

\section{Data collection}

Prior to the interview, participants were asked to reflect on their most recent experiences of making a cellulitis diagnosis, focusing on the typical presentations, challenging cases and differential diagnoses.

A topic guide, informed by a prior systematic review and interview study, ${ }^{8}$ was used to structure the interview (see online supplemental material). However, participants were urged to propose and/or expand on topics which they felt were relevant to their experience of diagnosis. New topics were then added to the topic guide for subsequent interviews.

\section{Data processing}

Interviews were audiorecorded and transcribed. Transcripts were checked (by MP) and data managed using QSR NVivo 12 software.

\section{Data analysis}

Analysis was inductive, searching for themes in the data. A structured, systematic, multistage approach to thematic analysis was followed. ${ }^{9}$ Coders immersed themselves in the data, by reading the dataset before coding. Data were coded manually by MP, with SIL also independently coding a third of the transcripts. A list of each code, with a brief description was then used to group the codes into theme piles. Themes were defined and refined, with subthemes also developed.

Uncertainties in coding and thematic organisation were resolved in discussion with the other authors. Data collection and analysis was concurrent. The final codebook was agreed by all authors and is presented in figure 1 . The interviewer kept a reflexive research diary, logging intuitive thoughts and immediate reflections after each interview. These reflections, as well as queries around data collection, handling and interpretation were then discussed at regular research meetings.

\section{RESULTS}

Twenty HCPs were interviewed (table 1 ). The age range was 29-67 years; 15 were female; 6 had $<10$ years of clinical experience, 9 had 11-20 years and 5 had $>20$ years. Interviews were conducted between 19 March and 11 June 2019, with a mean duration of 29 min.

\section{Main findings}

Four key themes were identified: (1) the patient presentation; (2) challenges leading to diagnostic uncertainty; (3) strategies to improve diagnosis; and (4) the need for an objective diagnostic aid, with further classification into subthemes. How the codes mapped onto the overarching themes are shown in table 2.

\section{Diagnosis of cellulitis}

The typical patient and risk factors

In general practice, the typical patient described by participants included older adults with comorbidities; concerns 
Codes used

- Trial of treatment guides diagnosis

- Discussing diagnosis with colleagues

- Time and safety netting approach

- Patients who self-diagnose and treat

- Approach when HCPs do not agree with patient self-diagnosis

- Patients involved with diagnosis with the HCP

- Typical cellulitis presentations

- Clinical features of cellulitis

- Factors that decrease the likelihood of cellulitis diagnosis

- Factors that increase the likelihood of cellulitis diagnosis

- Investigations to aid diagnosis

- Missed/delayed diagnosis of cellulitis (final diagnosis)

- Missed/delayed diagnosis of cellulitis (initial diagnosis)

- Patient finds it difficult to accept it is not cellulitis

- Reasons why cellulitis diagnosis is challenging

- Suggestions on what may improve diagnosis

- Views on diagnostic aids for HCP

- Views on diagnostic aids for patients

- Views on how well HCP make diagnosis

- Experience guides diagnosis

- Seeing patients part way through assessment and management

- Differential diagnoses

- Sepsis as a concern

- Medico legal issues as a factor

- Follow up of patients

- Most suitable HCP to diagnose cellulitis

- Fear of missing more serious differentials

- Clinical features to include in diagnostic algorithm

- Other factors influencing diagnosis

Figure 1 Standardised codebook used by two independent coders. HCP, healthcare professional of possible cellulitis cases were often raised by district nursing colleagues. Emergency care and acute services described people who presented with features of systemic compromise. Both infectious disease and general surgery services often managed intravenous drug users who were at risk of deeper infection.

Factors that HCPs stated increased the likelihood of cellulitis were features of systemic upset including fever, malaise, rigours; coexisting injury or infection such as tinea, superficial ulceration, previous history of cellulitis, previous history of dermatological conditions such as eczema, diabetes, immunosuppressive medications and those with no fixed abode with social and health risks. Bilateral symptoms were commonly described by participants as a factor increasing the likelihood of chronic, systemic pathologies rather than cellulitis.

\section{Confidence in diagnosis}

One dermatologist explained how being more aware of the differential diagnoses made them more likely to accurately diagnose cellulitis, especially compared with junior colleagues. Generally, HCPs with more clinical experience felt more confident with diagnosis, as they appreciated the presentation with more observed cases 'I would say it is just experience [helping diagnosis], a lot of the juniors that come into A\&E have not seen that many cellulitis [cases]' (P19, emergency care consultant, 10 years clinical experience).

Table 1 Characteristics of the participants

\begin{tabular}{|c|c|c|c|c|}
\hline Participant & Ethnicity & Clinical role & $\begin{array}{l}\text { Number of times they } \\
\text { have diagnosed cellulitis }\end{array}$ & $\begin{array}{l}\text { Time since they last } \\
\text { diagnosed cellulitis }\end{array}$ \\
\hline 1 & Asian British & GP & $>50$ & One week ago \\
\hline 3 & White Irish & GP & $>50$ & Three weeks ago \\
\hline 4 & White British & Acute medicine consultant & $>50$ & Last 4 weeks \\
\hline 7 & White British & Lymphoedema specialist nurse & $>50$ & One week ago \\
\hline 8 & Asian British & Emergency medicine consultant & $>50$ & Less than 1 week \\
\hline 9 & Asian British & Dermatology consultant & $10-50$ & Four weeks ago \\
\hline 10 & White British & District nurse & $>50$ & Last 3 months \\
\hline 14 & White British & Dermatology specialist nurse & $>50$ & Last 3 months \\
\hline 15 & White British & Dermatology consultant & $10-50$ & Last 12 months \\
\hline 16 & Mixed & Surgical trainee & $10-50$ & Last 4 weeks \\
\hline 17 & White British & Community advanced nurse practitioner & $>50$ & Less than 1 week \\
\hline 18 & White British & Dermatology trainee & $>50$ & Four weeks ago \\
\hline 19 & White British & Emergency medicine consultant & $>50$ & Last 3 months \\
\hline 20 & White British & Dermatology consultant & $>50$ & Less than 1 week \\
\hline
\end{tabular}

GP, general practitioner. 


\begin{tabular}{|c|c|c|}
\hline Themes & Subthemes & Codes \\
\hline \multirow[t]{7}{*}{$\begin{array}{l}\text { The patient } \\
\text { presentation }\end{array}$} & $\begin{array}{l}\text { The typical patient } \\
\text { and risk factors }\end{array}$ & $\begin{array}{l}\text { Typical cellulitis } \\
\text { presentations }\end{array}$ \\
\hline & & $\begin{array}{l}\text { Factors that } \\
\text { increase the } \\
\text { likelihood of } \\
\text { cellulitis diagnosis }\end{array}$ \\
\hline & $\begin{array}{l}\text { Confidence in } \\
\text { diagnosis }\end{array}$ & $\begin{array}{l}\text { Most suitable } \\
\text { HCP to diagnose } \\
\text { cellulitis }\end{array}$ \\
\hline & & $\begin{array}{l}\text { Experience guides } \\
\text { diagnosis }\end{array}$ \\
\hline & $\begin{array}{l}\text { Cases of } \\
\text { misdiagnoses }\end{array}$ & $\begin{array}{l}\text { Missed/delayed } \\
\text { diagnosis of } \\
\text { cellulitis (final } \\
\text { diagnosis) }\end{array}$ \\
\hline & & $\begin{array}{l}\text { Missed/delayed } \\
\text { diagnosis of } \\
\text { cellulitis (initial } \\
\text { diagnosis) }\end{array}$ \\
\hline & Differential diagnoses & $\begin{array}{l}\text { List of alternative } \\
\text { diagnosis }\end{array}$ \\
\hline \multirow{8}{*}{$\begin{array}{l}\text { Challenges } \\
\text { leading to } \\
\text { diagnostic } \\
\text { uncertainty }\end{array}$} & $\begin{array}{l}\text { Continuum of clinical } \\
\text { features }\end{array}$ & $\begin{array}{l}\text { Changes in clinical } \\
\text { presentation }\end{array}$ \\
\hline & A subjective diagnosis & $\begin{array}{l}\text { Reasons why } \\
\text { cellulitis diagnosis } \\
\text { is challenging }\end{array}$ \\
\hline & $\begin{array}{l}\text { Community } \\
\text { challenges }\end{array}$ & $\begin{array}{l}\text { Seeing patients } \\
\text { part way through } \\
\text { assessment and } \\
\text { management }\end{array}$ \\
\hline & & $\begin{array}{l}\text { Follow-up of } \\
\text { patients }\end{array}$ \\
\hline & $\begin{array}{l}\text { The role of 'defensive' } \\
\text { medicine }\end{array}$ & $\begin{array}{l}\text { Sepsis as a } \\
\text { concern }\end{array}$ \\
\hline & & $\begin{array}{l}\text { Medico legal issues } \\
\text { as a factor }\end{array}$ \\
\hline & & $\begin{array}{l}\text { Fear of missing } \\
\text { more serious } \\
\text { differentials }\end{array}$ \\
\hline & $\begin{array}{l}\text { Patient-specific } \\
\text { factors }\end{array}$ & $\begin{array}{l}\text { Other factors } \\
\text { influencing } \\
\text { diagnosis }\end{array}$ \\
\hline \multirow{4}{*}{$\begin{array}{l}\text { Strategies } \\
\text { to improve } \\
\text { diagnosis }\end{array}$} & Using time as a guide & $\begin{array}{l}\text { Time and safety } \\
\text { netting approach }\end{array}$ \\
\hline & Trial of treatment & $\begin{array}{l}\text { Trial of treatment } \\
\text { guides diagnosis }\end{array}$ \\
\hline & $\begin{array}{l}\text { Biochemical } \\
\text { investigations }\end{array}$ & $\begin{array}{l}\text { Investigations to } \\
\text { aid diagnosis }\end{array}$ \\
\hline & Seeking advice & $\begin{array}{l}\text { Discussing } \\
\text { diagnosis with } \\
\text { colleagues }\end{array}$ \\
\hline
\end{tabular}

Continued

\begin{tabular}{lll}
\hline Table 2 & Continued & \\
\hline Themes & Subthemes & Codes \\
\hline & Further education & $\begin{array}{l}\text { Suggestions on } \\
\text { what may improve } \\
\text { diagnosis }\end{array}$ \\
$\begin{array}{l}\text { The need for } \\
\text { an objective } \\
\text { diagnostic } \\
\text { aid }\end{array}$ & $\begin{array}{l}\text { A diagnostic algorithm } \\
\text { diagnostic aids for }\end{array}$ \\
& Indices for an & HCP \\
& algorithm & $\begin{array}{l}\text { Clinical features } \\
\text { to include in } \\
\text { diagnostic } \\
\text { algorithm }\end{array}$ \\
& &
\end{tabular}

HCP, health care professional.

A dermatology trainee felt seeing less cellulitis cases during their training compared with their senior colleagues historically, and therefore not getting as much exposure, hindered accurate diagnosis.

\section{Cases of misdiagnoses}

Trauma-related skin changes were frequently an initial misdiagnosis in the emergency department. When discussing cases of uncertainty, where cellulitis was the initial suspected diagnosis, one GP described a case of venous eczema which was managed with repeated antibiotics 'Generally anything that is red and hot on the legs is treated with antibiotics' (P1, GP,>13 years clinical experience). Chronic rashes were frequently seen by dermatology and infectious disease discussed lymphoma cases initially referred as cellulitis 'We did see [patients] coming in with 'Oh this must be a resistant cellulitis', have got a swollen limb that might be a little bit red and it turns out to be some horrible form of lymphoma' (P2, infectious disease consultant, 25 years clinical experience).

The importance of a correct diagnosis is key, as two participants discussed the possibility of prophylactic antibiotics for patients with recurrent cellulitis. A dermatology consultant explained how misdiagnosis can result in inappropriate and costly admissions to the ward.

\section{Differential diagnoses}

A frequent diagnosis of uncertainty for primary and emergency care was deep vein thrombosis (DVT), as the clinical features of cellulitis can overlap 'One thing that is always a problem is leg swelling... it is difficult to ascertain between DVT and cellulitis' (P8, emergency care consultant, 20 years clinical experience). Common differential diagnoses discussed by participants, which they observed in their clinical practice, with discriminating features from cellulitis that they described, are shown in table 3.

\section{Challenges leading to diagnostic uncertainty}

The continuum of clinical features

Participants described how the presentation of lower limb cellulitis changed as the episode ran its course. This was influenced by when patients seek clinical review and 
Table 3 Differential diagnoses of lower limb cellulitis discussed by participants

\section{Differential diagnoses Key differentiating factors from cellulitis}

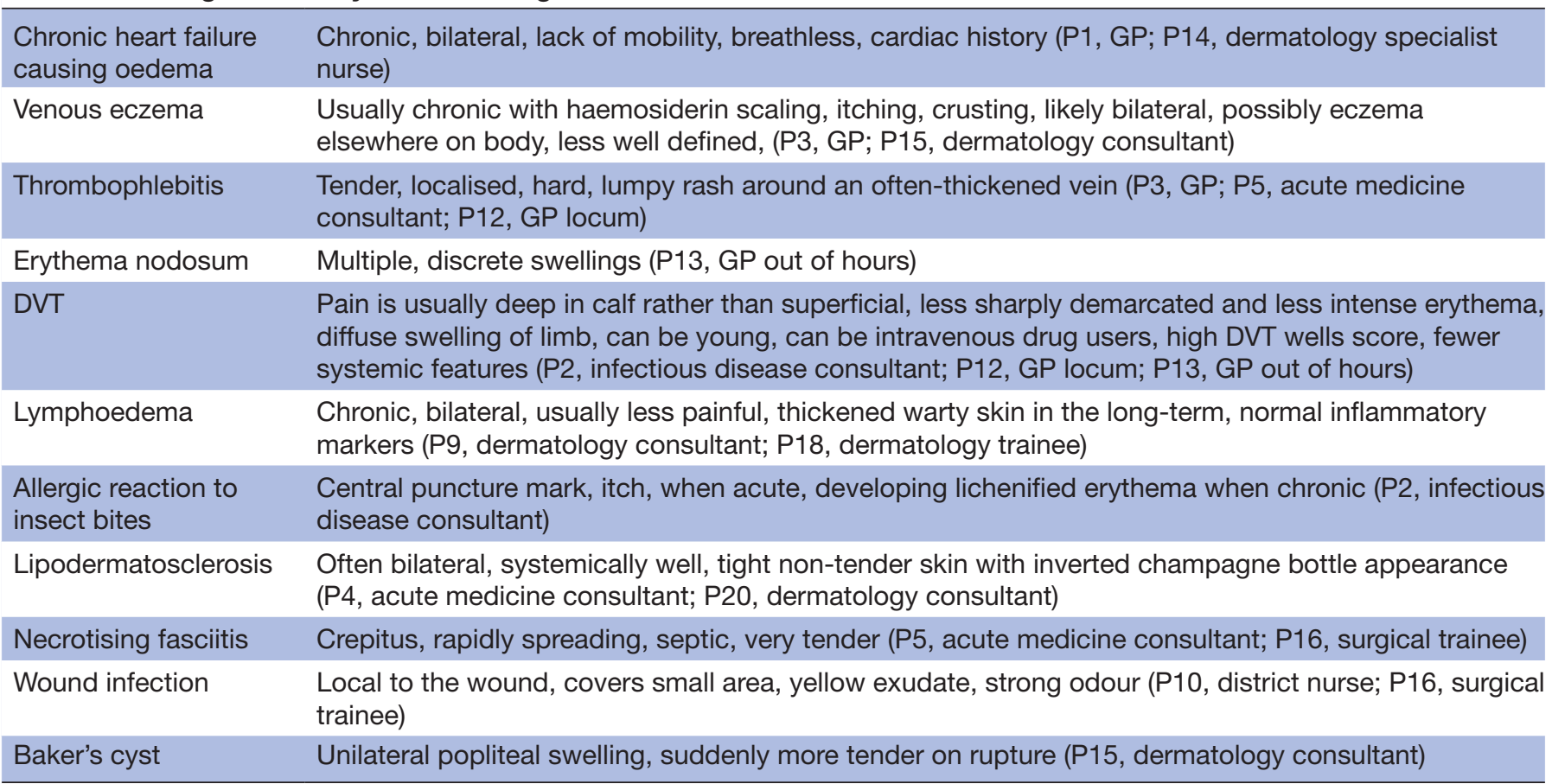

DVT, deep vein thrombosis; GP, general practitioner.

meant that different specialties observed clinical features at varying stages of cellulitis.

In dermatology services, presentations were seen later in the episode. However, partial treatment and response did make the diagnosis challenging as the initial typical features of cellulitis may then vary. However, seeing patients later in the journey allowed dermatologists to appreciate the progression of clinical features 'I learnt to appreciate much more that [cellulitis] is coming up, it is happening and that it is fading away...When I was [junior], I was seeing [cellulitis] at the beginning and middle stages, trying to diagnose it, but in dermatology you're seeing it more at that other end of the spectrum...so I think there is a lot [to be] learnt about seeing that pattern developing and progressing and then resolving' (P18, dermatology trainee, 8 years clinical experience).

Importantly for dermatologists, other more serious pathologies such as a DVT had often been ruled out.

\section{A subjective diagnosis}

One GP explained how there is no specific test that can aid diagnosis, thus subjective assessment can lead to different diagnoses 'I think the fact that there is no specific diagnostic test... and two different people can look at [possible cellulitis) and come up with two different answers' (P1, GP, $>13$ years clinical experience). She added how this is further influenced by previous experiences, including how long and where HCPs have trained.

\section{Community challenges}

In the community, additional challenges for GPs were not being familiar with the patient's background history, seeing a patient for the first time or taking over care part way through the patient journey. Working as a locum doctor with a lack of follow-up available, often led to treatment when unsure of the diagnosis 'You've not met the patient before and sometimes you're not going to be able to follow them up so you probably are more likely to give antibiotics' (P12, GP locum, 7 years clinical experience). Limited resources to see patients, such as not being able to conduct an urgent home visit, also influenced diagnosis and subsequent management by GPs.

\section{The role of 'defensive' medicine}

HCPs in the community, emergency care and surgery were particularly wary of missing a more serious diagnosis, which needed to be ruled out first, such as DVT and necrotising fasciitis 'I think you would want to rule out DVT first because if you miss that then that is... a problem' (P1, GP, >13 years clinical experience; P16, female, surgical trainee, 5 years clinical experience). Many HCPs also mentioned 'sepsis' when discussing clinical features and diagnosis. This may be leading to an over diagnosis of cellulitis due to concerns of medicolegal complaints of missing an infection which could then get worse 'We're all risk adverse aren't we? We would rather make sure we weren't sued because we had missed someone with an infection' (P2, infectious disease consultant, 25 years clinical experience). 
Patient-specific factors

Participants found people with pigmented skin, lymphoedema and with non-specific symptoms particularly difficult to diagnose in the acute setting 'One of these classical patients that comes in hasn't got a rash... [or] the features of swelling, redness, rash and pain in the leg but they come in none specifically unwell...I think those patients are much trickier [to diagnose cellulitis]' (P5, acute medicine consultant, 16 years clinical experience). One nurse described another diagnostic challenge was when a patient presents with chronic skin changes or a recent episode of cellulitis with continuing signs 'People with chronic red [legs], their legs are red most of the time... the skin takes so long to settle, so they could have had cellulitis four weeks ago and it is still red' (P17, advanced nurse practitioner, 20 years clinical experience).

\section{Strategies used to reduce uncertainty \\ Using time as a guide}

In cases where the HCP was not sure of the diagnosis, different strategies were employed. Using time to allow further clinical features to develop, with appropriate safety netting was a commonly used approach. This was easier when follow-up appointments were available in the community, but was also done in the acute setting 'So if they were well...then I would bring them back to clinic the next day or two' (P4, acute medicine consultant, 17 years clinical experience). But follow-up in secondary care was difficult, often not done and can be a missed opportunity to learn from incorrect diagnoses previously.

\section{Trial of treatment}

Some HCPs started antibiotics for a suspected cellulitis and reviewed the response to help provide the diagnosis retrospectively 'Cellulitis... was the easiest thing to try and treat so I think that definitely pushed [me] to try some antibiotics and see if this is an infection' (P11, GP trainee, 6 years clinical experience). A major concern highlighted by one GP with this approach was antibiotic resistance and side effects. However, overall, there was a common understanding in primary care why this approach was taken in some instances.

\section{Biochemical investigations}

In primary care, one doctor described how blood tests and cultures were rarely done to diagnose cellulitis, as such patients would need to be seen in secondary care. Blood cultures were requested by the infectious disease physician if it was an atypical infection, but a challenge described by one dermatology consultant was that organisms are not isolated in the majority of patients. Swabs were done for discharging wound infections, mainly by district nurses or prior to discussion with microbiology, when see by dermatologists.

An emergency physician and surgical trainee explained how blood tests and imaging such as X-rays are important to check for osteomyelitis. The blood tests commonly requested by secondary care HCPs were white cell count
(WCC) and C-reactive protein (CRP) for infection with one dermatologist stating how changes in blood test results were important when taking referrals for suspected cellulitis '[With cellulitis]...you expect a) it is unilateral, b) you want some inflammatory markers which are raised, at least a reasonable WCC and CRP and if it is normal it is not going to be cellulitis' ( $\mathrm{P}$ 9, dermatology consultant, 10 years clinical experience). However, one challenge with interpreting blood tests was in the group partially treated with antibiotics, who have improving blood tests but limited clinical response. A biomarker or point of care test for cellulitis was suggested as investigations to aid diagnosis by one dermatology consultant and one GP, respectively.

\section{Seeking advice}

Another approach during uncertainty was to discuss with colleagues. In the community the nurse may ask the GP to review and vice versa. In hospital, specialists in infectious disease, dermatology, microbiology and general/plastic surgeons are most often contacted for review.

\section{Further education}

Many HCPs mentioned teaching sessions to improve diagnosis, both at the undergraduate and postgraduate level. One GP stated that real-life clinical cases were felt to be important for teaching, rather than focusing on pictures 'It is all very well seeing pictures but pictures aren't that helpful sometimes, it is how it feels sometimes that makes a difference and actually seeing it in the flesh is very different to seeing even good quality pictures, so I do think that clinical exposure [is important]' (P13, GP, 20 years clinical experience).

A dermatology consultant suggested that a key area of education among HCPs was being aware of differential diagnoses for frontline services 'It is not something people will have put a lot of thought into, the differentials, and I think the focus needs to be on teaching the frontline staff' (P15, dermatology consultant, 18 years clinical experience).

One trainee who worked in a specialist cellulitis clinic found that seeing many cases helped improve her recognition of cellulitis.

\section{The need for an objective diagnostic aid}

\section{A diagnostic algorithm}

Many participants mentioned developing a diagnostic algorithm, similar to the Wells score for DVT. A GP explained how this may also help GPs make a validated clinical decision when colleagues such as district nurses are suspecting cellulitis and the patient cannot be seen quickly. A dermatology nurse described how she often used checklists and how an algorithm would help HCPs not to miss any clinical features [A checklist] could help people that weren't experienced or confident enough... it just gives you something to think about like "oh I hadn't thought about the heat" (P14, dermatology nurse, 9 years clinical experience). 
One dermatology consultant suggested that a diagnostic checklist should be more of an educational tool to help rule out other differential diagnoses 'For a diagnostic checklist you almost want it to be provided as an education tool with photographs and descriptions...so that people can put these differential diagnoses into their head' (P15, dermatology consultant, 18 years clinical experience).

A dermatology trainee felt that the indices of a checklist would have to reflect how cellulitis changes through the course of the episode. Other challenges described by participants, regarding developing an algorithm were the number of alternative diagnoses, with features that often overlapped with cellulitis and vague initial features. Another concern highlighted by a dermatology consultant was that algorithms will miss patients who may present with atypical features 'Sometimes the trouble with guidelines, algorithms...you could probably cover 95\% but does it mean that actually the atypical 5\% then [do not] get diagnosed?' (P20, dermatology consultant, 42 years clinical experience).

\section{Indices for an algorithm}

The key clinical features that HCPs suggested to include in a diagnostic algorithm for lower limb cellulitis were unilateral, pain, erythema, warmth of limb, fever, swelling, acute onset, trauma to the limb, break in the skin, single area affected, clear demarcation, exudate, influenza like malaise, tracking rash, shiny, tenser skin, previous cellulitis, coexisting immunosuppression, coexisting skin conditions, clinical observations for sepsis, negative Wells score and patient concern. No HCP suggested blood tests were a priority in the algorithm, but a GP trainee suggested it could be included in a modified algorithm in secondary care, similar to the CURB-65 score used for pneumonia.

Additional quotes from participants are shown in table 4 .

\section{DISCUSSION}

\section{Summary}

This study found that the presentation of lower limb cellulitis changes as the episode progresses, leading to variation in the clinical features, seen in different clinical settings. This may be reflected in the range of typical differential diagnoses that specialties discussed and has been described in literature. ${ }^{10}$

Clinical experience was described as an important factor in making a more accurate diagnosis. Dermatologists have previously been suggested as the ideal HCP to diagnose cellulitis. ${ }^{11}$ However, the clinical reasoning behind a diagnosis was contradictory between some HCPs.

A core group of clinical features to diagnose cellulitis were suggested. But the challenge is that these features can overlap with other pathologies, irrespective of how likely these are. ${ }^{12}$ More serious pathologies then need to be ruled out first, both for the safety of the patient and to avoid medico-legal consequences.
Suggestions to improve the accuracy of diagnoses included developing a diagnostic algorithm which could objectively help HCPs with different levels of experience. ${ }^{13}$ The challenge with a diagnostic algorithm is that it would need to incorporate the various stages of a cellulitis episode and therefore various versions of an algorithm might be required.

Importantly, having a greater understanding of the alternative diagnoses is required, especially when the features are vague, atypical or not responding to antibiotic treatment. Educating both doctors and nurses, using real-life clinical scenarios and a focus on differential diagnoses, was also discussed and may be an initial feasible approach to improve diagnostic accuracy. A visually based computerised diagnostic decision support system, focusing on differential diagnoses, has been shown to improve the diagnostic accuracy of cellulitis. ${ }^{3}$

\section{Strengths and limitations}

A key strength of this study is that participants were included nationally around the UK, across various specialties that commonly diagnose cellulitis, with both nurses and doctors of varying clinical experience.

Like similar studies, the size and scope of the sample population is a limitation of this work. While we argue that our findings are transferable to other settings, we acknowledge that those interviewed were perhaps more interested and better informed about dermatology than many HCPs. This was a function of our purposive sampling, and the likelihood that those interested in cellulitis were more likely to consent to an interview. Furthermore, the participants in this study were mainly female doctors. This may not be representative of the workforce in non-UK countries; therefore the transferability of our findings may be limited.

Some participants were unable to fully describe their clinical rationale behind diagnostic decisions during the interview. This may be because they have developed an intuitive, pattern-recognition, approach in decisionmaking with experience. Such heuristic diagnostic processes in dermatology are well documented. ${ }^{14}$

As the interviewer was a fellow clinician, interviewees may not have fully shared the details of cases that were misdiagnosed or where diagnoses were delayed due to social desirability bias or fear of litigation. Clinical researcher bias was unavoidable, as the interviewer had clinical insight into cellulitis. However, non-clinicians within the broader authorship group were also involved with coding and analysis of the interviews.

Three participants were known to the interviewer, which can lead to response bias, however the interviewer felt this also allowed an honest, open discussion.

\section{Comparison with existing literature}

To our knowledge, this is the first interview study undertaken with HCPs, discussing their experiences of cellulitis diagnosis. Our findings on the clinical features of cellulitis, differential diagnoses and also the need to be 


\section{Table 4 Additional quotes from participants, grouped into themes and subthemes}

\begin{tabular}{|c|c|c|}
\hline Themes & Subthemes & Participant quotes \\
\hline \multirow[t]{3}{*}{$\begin{array}{l}\text { The patient } \\
\text { presentation }\end{array}$} & $\begin{array}{l}\text { Confidence in } \\
\text { diagnosis }\end{array}$ & $\begin{array}{l}\text { 'I probably thought more presentations were [cellulitis] as a junior doctor...I probably didn't really recognise } \\
\text { that sort of stretched skin appearance. I think that has come along as part of just experience over the years, so } \\
\text { I probably diagnosed more cellulitis inappropriately as a more junior doctor' (P13, GP out of hours, } 20 \text { years } \\
\text { clinical experience) }\end{array}$ \\
\hline & $\begin{array}{l}\text { Cases of } \\
\text { misdiagnoses }\end{array}$ & $\begin{array}{l}\text { 'One of the nurse practitioners had seen ankle swelling and the patient thought it...he played some cricket two } \\
\text { or three days ago and after one or two days the swelling appeared and she thought that it was just a sprain but } \\
\text { next day he represented, I saw him and it looked more like cellulitis because it was quite red, localised area...on } \\
\text { close examination I could see a couple of scratches around the ankle so that was maybe the source of cellulitis } \\
\text { spreading on the leg' (P8, emergency care consultant, } 20 \text { years clinical experience) }\end{array}$ \\
\hline & & $\begin{array}{l}\text { 'There are too many chronic rashes that get referred [to dermatology] as cellulitis' (P18, dermatology trainee, } 8 \\
\text { years clinical experience) }\end{array}$ \\
\hline $\begin{array}{l}\text { Challenges } \\
\text { leading to } \\
\text { diagnostic }\end{array}$ & $\begin{array}{l}\text { Continuum } \\
\text { of clinical } \\
\text { features }\end{array}$ & $\begin{array}{l}\text { 'Usually the patient is already admitted...[the referring team] have tried [multiple antibiotics], but nothing is } \\
\text { happening, "please can you come and tell us what is going on?'” (P9, dermatology consultant, } 10 \text { years clinical } \\
\text { experience) }\end{array}$ \\
\hline
\end{tabular}

'There are varying ranges of erythema, from a little bit of light pinkness to rip roaring hot red, tender, well demarcated, unilateral; the classic sort of textbook stuff' (P18, dermatology trainee, 8 years clinical experience)

'Virtually every patient that I see...they have had their $\mathrm{d}$-dimer and their duplex done so [DVT] is usually a diagnosis that has been excluded' (P20, dermatology consultant, 42 years clinical experience)

Community 'If you know the patient and you know that they have recurrent cellulitis, someone had seen it like a district nurse challenges and it is Friday afternoon and you can't get out [for a visit]. you would make a judgement call' (P1, GP, >13 years clinical experience)

The role of 'We're so much more aware of things like sepsis...looking at any kind of signs of infection' (P10, district nurse, 25 'defensive' years clinical experience) medicine

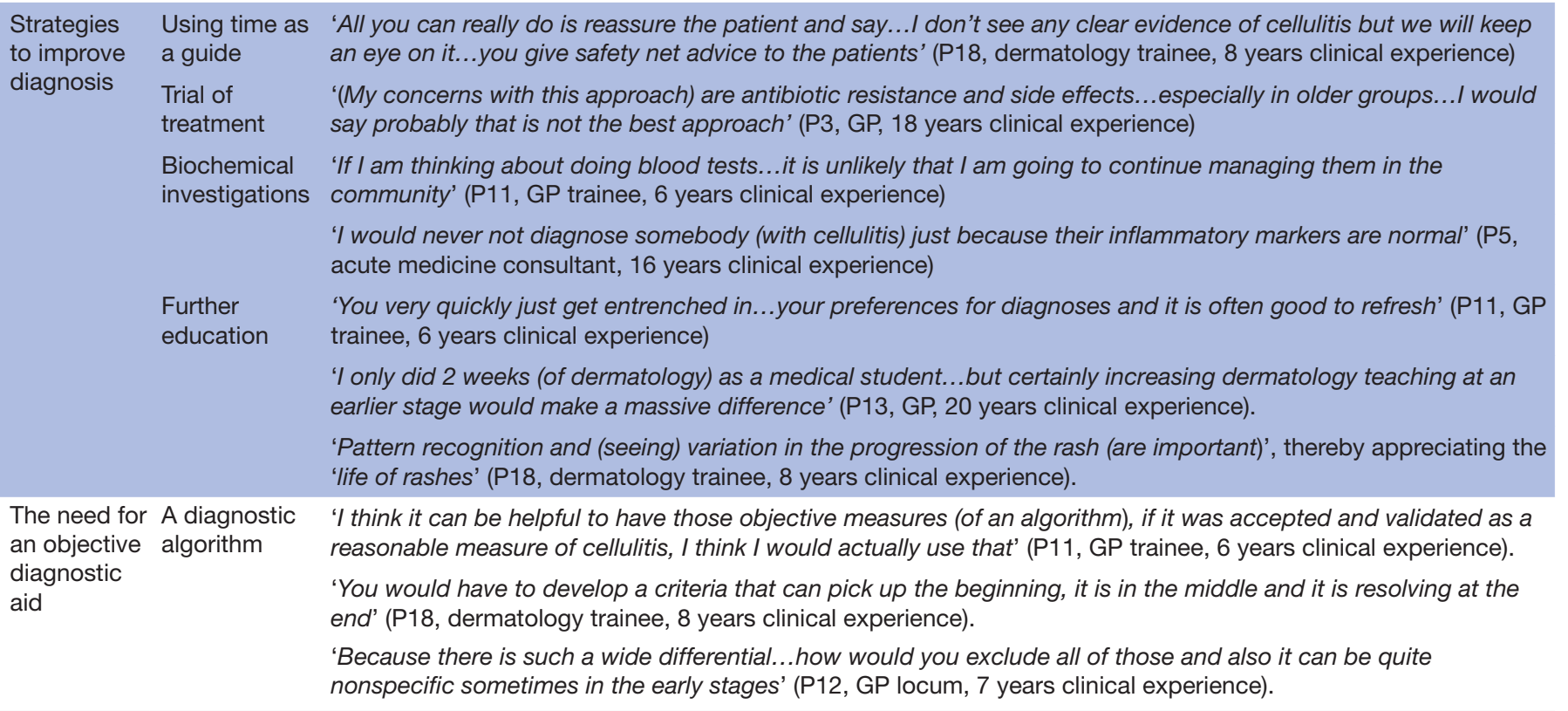

GP, general practitioner.

aware of mimics have been described in previous review articles. ${ }^{10}$ A previous review also described cases of misdiagnosis and emerging approaches to improve diagnoses, ${ }^{815}$ which were echoed in this study. The diagnostic challenges of infection in primary care, due to atypical presentations and lack of diagnostic tests, have previously been described. ${ }^{16}$ Using treatments such as antibiotics as diagnostic aids and discussing with colleagues when uncertain about a diagnosis are common strategies. ${ }^{17} 18$ Litigation and fear missing a diagnosis has also been well documented in literature. ${ }^{19}$

\section{Implications for research and practice}

This study has highlighted that HCPs need to be aware that cellulitis can present with different features at various stages of the acute episode and need to consider the cellulitis mimics. With a current shift in healthcare resulting in trained nurses now managing more acute presentations, ${ }^{20}$ upskilling nurses in cellulitis could be part of the solution.

Many HCPs felt confident in making an accurate diagnosis, often guided by experience and intuition, but found it difficult to verbalise the key distinguishing features. 
This makes it difficult for the clinical experience to be shared among other colleagues, especially less experienced or junior HCPs. Acquiring this insight is important to improve diagnostic accuracy, which can prevent avoidable antibiotic prescribing and hospital admissions. To overcome this, further qualitative research is required to identify the clinical reasoning behind the expert process of making a diagnosis, perhaps using clinical cases and pictures. This will form the basis of the proposed solution of focused education and clinical features to be included in a diagnostic aid. The challenge with further education for HCPs is that information needs to be accessible for everyone, while information overload can lead to a reduction in the quality of decisions. ${ }^{21}$

Some indices and risk factors for a diagnostic algorithm have been identified in this study and previous studies, ${ }^{22}$ as well as key distinguishing features from differential diagnosis, but these need validating with larger studies and an expert consensus setting exercise.

\section{CONCLUSION}

This interview study has shown that cellulitis is a complex diagnosis. Not only does the core features overlap with other diagnoses, the presentation of cellulitis changes as the episode progresses. Although cellulitis is a common diagnosis to make, and while further research in developing diagnostic aids needs to be undertaken, simply being aware of the cellulitis mimics may help improve diagnostic accuracy.

Acknowledgements The authors would like to thank the participants who were interviewed and the professional transcriber Claire Poxon. We also want to thank the Royal College of General Practitioners for supporting this study. The views expressed in this paper are those of the authors and not necessarily those of the National Health Service, the National Institute for Health Research or the Department of Health.

Contributors MP was involved with the design of the study, collection and analysis of data, drafting the manuscript and final approval of the manuscript. SIL, NJL, PS, JK, KST and PL were involved with the design of the study, analysis of data, drafting the manuscript and final approval of the manuscript.

Funding This study was supported by the Scientific Foundation Board of the Royal College of General Practitioners (grant SFB 2018-31).

Competing interests None declared.

Patient consent for publication Not required.

Provenance and peer review Not commissioned; externally peer reviewed.

Data availability statement № data are available.

Open access This is an open access article distributed in accordance with the Creative Commons Attribution Non Commercial (CC BY-NC 4.0) license, which permits others to distribute, remix, adapt, build upon this work non-commercially, and license their derivative works on different terms, provided the original work is properly cited, appropriate credit is given, any changes made indicated, and the use is non-commercial. See: http://creativecommons.org/licenses/by-nc/4.0/.

ORCID iD

Mitesh Patel http://orcid.org/0000-0003-3975-4689

\section{REFERENCES}

1 Lazzarini L, Conti E, Tositti G, et al. Erysipelas and cellulitis: clinical and microbiological spectrum in an Italian tertiary care hospital. $J$ Infect 2005;51:383-9.

2 Weng QY, Raff AB, Cohen JM, et al. Costs and consequences associated with misdiagnosed lower extremity cellulitis. JAMA Dermatol 2017;153:141-6.

3 David CV, Chira S, Eells SJ, et al. Diagnostic accuracy in patients admitted to hospitals with cellulitis. Dermatol Online J 2011;17:1.

4 Patel M, Lee SI, Akyea RK, et al. A systematic review showing the lack of diagnostic criteria and tools developed for lower-limb cellulitis. Br J Dermatol 2019;181:1156-65.

5 Thomas KS, Brindle R, Chalmers JR, et al. Identifying priority areas for research into the diagnosis, treatment and prevention of cellulitis (erysipelas): results of a James Lind alliance priority setting partnership. Br J Dermatol 2017;177:541-3.

6 Patel M, Lee SI, Levell NJ, et al. Confidence of recurrent cellulitis self-diagnosis among people with lymphoedema: a qualitative interview study. Br J Gen Pract 2020;70:e130-7.

7 Guest G, Bunce A, Johnson L. How many interviews are enough? an experiment with data saturation and variability. Field Methods 2006;18:59-82.

8 Patel M, Lee SI, Thomas KS, et al. The red leg dilemma: a scoping review of the challenges of diagnosing lower-limb cellulitis. $\mathrm{Br} \mathrm{J}$ Dermatol 2019;180:993-1000.

9 Braun V, Clarke V. Using thematic analysis in psychology. Qual Res Psychol 2006;3:77-101.

10 Bailey E, Kroshinsky D. Cellulitis: diagnosis and management. Dermatol Ther 2011;24:229-39.

11 Levell NJ, Wingfield CG, Garioch JJ. Severe lower limb cellulitis is best diagnosed by dermatologists and managed with shared care between primary and secondary care. $\mathrm{Br} J$ Dermatol 2011;164:1326-8.

12 Raff AB, Kroshinsky D. Cellulitis: a review. JAMA 2016;316:325-37.

13 Pallin DJ, Bry L, Dwyer RC, et al. Toward an objective diagnostic test for bacterial cellulitis. PLoS One 2016;11:e0162947.

14 Lowenstein EJ. Dermatology and its unique diagnostic heuristics. $J$ Am Acad Dermatol 2018;78:1239-40.

15 Edwards G, Freeman K, Llewelyn MJ, et al. What diagnostic strategies can help differentiate cellulitis from other causes of red legs in primary care? BMJ 2020;368:m54.

16 McKelvie S, Moore A, Croxson C, et al. Challenges and strategies for general practitioners diagnosing serious infections in older adults: a UK qualitative interview study. BMC Fam Pract 2019;20:56.

17 Hayward GN, Moore A, Mckelvie S, et al. Antibiotic prescribing for the older adult: beliefs and practices in primary care. J Antimicrob Chemother 2019;74:791-7.

18 Alam R, Cheraghi-Sohi S, Panagioti M, et al. Managing diagnostic uncertainty in primary care: a systematic critical review. BMC Fam Pract 2017;18:79.

19 Birks Y, Aspinal F, Bloor K. Understanding the drivers of litigation in health services. The Kings Fund, University of York, 2018.

20 Imison C, Castle-Clarke S, Watson R. Reshaping the workforce to deliver the care patients needs. Research report. Nuffield Trust, 2016.

21 Kumar A, Maskara S. Coping up with the information overload in the medical profession. J Biosci Med 2015;03:124-7.

22 Quirke M, Ayoub F, McCabe A, et al. Risk factors for nonpurulent leg cellulitis: a systematic review and meta-analysis. $\mathrm{Br} J$ Dermatol 2017;177:382-94. 